TITLE:

\title{
Ternary Blend Polymer Solar Cells Based on Wide-Bandgap Polymer PDCBT and Low-Bandgap Polymer PTB7-Th
}

\section{AUTHOR(S):}

Kim, Do Hyung; Shimizu, Ryosuke; Ohkita, Hideo

\section{CITATION:}

Kim, Do Hyung ... [et al]. Ternary Blend Polymer Solar Cells Based on Wide-Bandgap

Polymer PDCBT and Low-Bandgap Polymer PTB7-Th. Chemistry Letters 2018, 47(8): 10591062

\section{ISSUE DATE:}

2018-06-21

URL:

http://hdl.handle.net/2433/233072

\section{RIGHT:}

(c) 2018 The Chemical Society of Japan; 発行元の許可を得て登録してい ます:;この論文は出版社版でありません。引用の際には出版社版をご 確認ご利用ください。; This is not the published version. Please cite only the published version. 


\title{
Ternary Blend Polymer Solar Cells Based on Wide-Bandgap Polymer PDCBT and Low- Bandgap Polymer PTB7-Th
}

\author{
Hyung Do Kim, ${ }^{1}$ Ryosuke Shimizu, ${ }^{1}$ and Hideo Ohkita ${ }^{1}$ \\ ${ }^{1}$ Department of Polymer Chemistry, Graduate School of Engineering, Kyoto University,
} Katsura, Nishikyo, Kyoto 615-8510, Japan

E-mail: ohkita@photo.polym.kyoto-u.ac.jp

Light-harvesting efficiency can be prominently increased by using ternary blend polymer solar cells, in which a widebandgap crystalline polymer is incorporated into a binary blend of a low-bandgap polymer and a fullerene derivative. This is partly due to the complementary absorption bands over a wide wavelength range, and partly ascribed to the thick photoactive layer. As a result, the best power conversion efficiency of $9.40 \%$ was obtained for the ternary blend device with a thickness of $\approx 300 \mathrm{~nm}$.

Polymer solar cells have attracted a great deal of attention as a next-generation solar cell because they have great advantages of lightweight, flexible, transparent, and low-cost production by printing techniques. ${ }^{1,2}$ In the last decade, the photovoltaic performance has been steadily improved. Currently, a power conversion efficiency (PCE) of more than $10 \%$ has been reported by many research groups. ${ }^{3-6}$ Although this efficiency is comparable to that reported for amorphous silicon solar cells, it is still required to improve the photovoltaic performance of polymer solar cells for a wide range of practical applications. For further improvements, many studies have been devoted to improving all the photovoltaic parameters, especially short-circuit current density $J_{\mathrm{SC}}$ and open-circuit voltage $V_{\mathrm{OC}}{ }^{5-8}$ In the past decade, various low-bandgap polymers have been developed to harvest the near-IR light that has the maximum photon density in the solar light, leading to the improvement in $J_{\mathrm{SC}}{ }^{5,6}$ At the same time, these low-bandgap polymers have been designed to have lower energy levels of the highest occupied molecular orbital (HOMO), which are necessary for the improvement in $V_{\mathrm{OC}}{ }^{7,8}$ Consequently, as mentioned above, more than $10 \%$ has been achieved. However, this approach has limitations for further improvement in $J_{\mathrm{SC}}$. This is because most of organic materials have a narrow absorption bandwidth, which is typically as narrow as $200 \mathrm{~nm}$ at most. Thus, it would be difficult for one conjugated polymer to cover a wide wavelength range from visible to near-IR region in the solar light.

Ternary blend polymer solar cells are one of new approaches to solving such challenging issues. ${ }^{9-14}$ Recently, we have developed ternary blend polymer solar cells based on a wide-bandgap polymer, poly(3-hexylthiophene) (P3HT), a fullerene derivative (PCBM), and a near-IR dye molecule such as a silicon phthalocyanine derivative $(\mathrm{SiPc}) .{ }^{9-11}$ The addition of such near-IR dye can easily expand the light-harvesting wavelength range up to the near-IR region, and hence can boost the photocurrent furthermore. We also have demonstrated how molecular design of near-IR dye molecules can control their location in ternary blend solar cells to improve the photocurrent generation effectively. ${ }^{11}$ On the other hand, the ternary blends consisting of two donor polymers and fullerene derivative have recently attracted much attention because they can cover a wider range of the solar light from visible to near-IR region simultaneously owing to wider absorption bandwidths of donor conjugated polymers. In addition to such an excellent lightharvesting efficiency, it has been reported that $V_{\mathrm{OC}}$ and fill factor (FF) can be improved by introducing a third polymer into the binary blend system. ${ }^{12-14}$

Herein, we have fabricated ternary blend polymer solar cells in which wide-bandgap crystalline polymer, poly[5,5'bis(2-butyloctyl)-(2,2'-bithiophene)-4,4'-dicarboxylate-alt-

5,5'-2,2'-bithiophene] (PDCBT) is introduced into the blend of
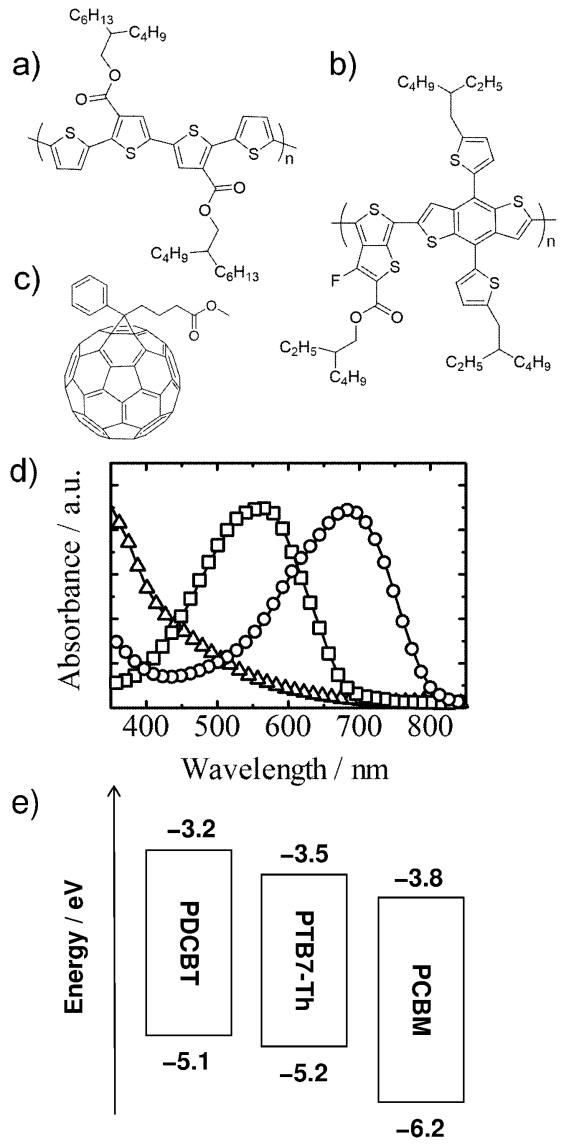

Figure 1. Chemical structures of materials employed in this study: a) PDCBT, b) PTB7-Th, and c) PCBM. d) Absorption spectra of two donor polymers and PCBM: PDCBT (open squares), PTB7-Th (open circles), and PCBM (open triangles). e) Energy diagram of these materials employed. Each value in the upper and lower side represents LUMO and HOMO energy levels, respectively. 
low-bandgap polymer, poly[4,8-bis(5-(2-ethylhexyl)thiophen2-yl)benzo[1,2- $\left.b ; 4,5-b^{\prime}\right]$ dithiophene-2,6-diyl-alt-(4-(2ethylhexyl)-3-fluorothieno[3,4- $b$ ] thiophene-)-2-carboxylate2,6-diyl] (PTB7-Th) and PCBM as shown in Figure 1a-c. As shown in Figure 1d, this two-donor polymer blend can expand the light-harvesting wavelength, and hence can contribute to boosting the photocurrent effectively. As shown in Figure 1e, a highly efficient charge transfer can be expected at the interface of PDCBT/PCBM and PTB7-Th/PCBM in the ternary blend devices. As a result, the ternary blend polymer solar cells exhibit an efficient light harvesting over a wide-range and charge collection even with a thickness of $300 \mathrm{~nm}$, thereby leading to an overall PCE of $9.40 \%$ larger by about $25 \%$ than that for binary control device.

Ternary blend polymer solar cells based on wide and lowbandgap donor polymers and PCBM were fabricated as follows. A hole-transporting buffer layer $(40 \mathrm{~nm})$ of $\operatorname{poly}(3,4-$ ethylenedioxythiophene) with poly(4-styrenesulfonate) (PEDOT:PSS, H. C. Starck Clevios PH500) was coated atop a UV-ozone cleaned Indium-doped tin-oxide (ITO)-coated glass substrate with a sheet resistance of $10 \Omega$ per square by spincoating at $3000 \mathrm{rpm}$, and then dried on a hot plate at $140{ }^{\circ} \mathrm{C}$ for $10 \mathrm{~min}$ in air. Before the spin-coating, the solution of PEDOT:PSS was filtered with a PTFE syringe filter with a pore size of $0.45 \mu \mathrm{m}$. The photoactive films employed in this study were prepared on the ITO/PEDOT:PSS substrate by spincoating at different spin rates for $60 \mathrm{~s}$ in the nitrogen atmosphere, and subsequently dried under vacuum at room temperature for 15 min. A blend solution of PDCBT/PTB7Th/PCBM was prepared by dissolving donor polymers and PCBM with a different composition ratio of $x: 1-x: 1.5 \mathrm{mg}$ in $y \mathrm{~mL}$ of chlorobenzene with $3 \%$ volume ratio of $1,8-$ diiodooctane (DIO). The blend solution was stirred at $80{ }^{\circ} \mathrm{C}$ overnight. The thickness of blend films was summarized in Table S1 (see Supporting Information (SI)). The buffer layer of PFN-Br $(5 \mathrm{~nm})$ or $\mathrm{Ca}(3 \mathrm{~nm})$ was deposited on the photoactive layer by spin-coating at $3000 \mathrm{rpm}$ for $60 \mathrm{~s}$ or thermal evaporation under high vacuum at a pressure of $2 \times$ $10^{-4} \mathrm{~Pa}$, respectively. Finally, $80 \mathrm{~nm}$ of aluminum top electrode was deposited by vacuum evaporation on top of the buffer layer. Consequently, the device layered structure obtained was as follows: ITO|PEDOT:PSS|PDCBT/PTB7$\mathrm{Th} / \mathrm{PCBM} \mid \mathrm{PFN}-\mathrm{Br}$ or $\mathrm{Ca} / \mathrm{Al}$. The effective area of the device was $0.07 \mathrm{~cm}^{2}$. Note that there is no distinct difference in the photovoltaic performance of both devices with $\mathrm{PFN}-\mathrm{Br} / \mathrm{Al}$ and $\mathrm{Ca} / \mathrm{Al}$ electrodes.

$J-V$ characteristics were measured with a direct-current (DC) voltage and current source/monitor (Keithley, 2611B) in the dark and under the illumination with AM1.5G simulated solar light with $100 \mathrm{~mW} \mathrm{~cm}{ }^{-2}$. The light intensity was corrected with a calibrated silicon photodiode reference cell (Bunkoukeiki, BS-520). External quantum efficiency (EQE) spectra were measured with a spectral response measurement system (Bunkoukeiki, ECT-250D). The power of the incident monochromatic light was kept under $0.05 \mathrm{~mW} \mathrm{~cm}^{-2}$, which was measured with a calibrated silicon reference cell (Bunkoukeiki, BS-520BK). All these measurements were performed under a nitrogen atmosphere at room temperature. Absorption spectra were measured with a spectrophotometer (Hitachi, U-4100). The thickness of the photoactive layer were measured with an atomic force microscope (Shimadzu, SPM-9600) with a silicon a)

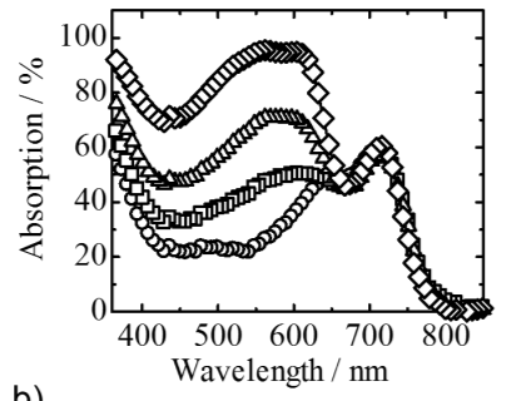

b)

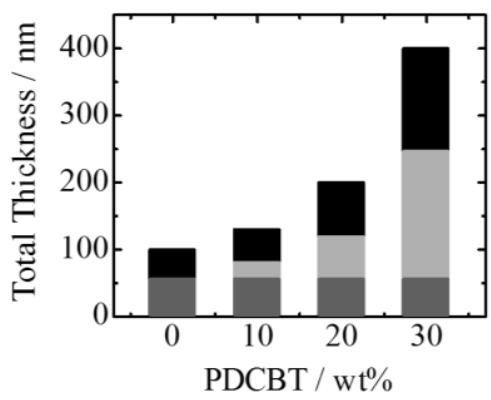

Figure 2. a) Absorption spectra of PDCBT/PTB7-Th/PCBM ternary blend with different weight fractions of PDCBT, which were measured in the transmission mode: $0 \mathrm{wt} \%$ (open circles), $10 \mathrm{wt} \%$ (open squares), $20 \mathrm{wt} \%$ (open triangles), and $30 \mathrm{wt} \%$ (open diamonds). b) Estimated total film thickness and each composition ratio of the PDCBT/PTB7Th/PCBM ternary blend films as a function of the different amount of PCDTBT: PDCBT (light gray), PTB7-Th (dark gray), and PCBM (black). The thickness of each component fraction was estimated on the basis of the absorbance and each absorption coefficient of materials employed.

probe (Olympus, a force constant of $\approx 0.15 \mathrm{~N} \mathrm{~m}^{-1}$ ) in contact mode.

Figure 2a shows the absorption spectra of PDCBT/PTB7Th/PCBM ternary blend films with various weight fractions of PDCBT, which were measured in the transmission mode. Here, the weight ratio of PDCBT/PTB7-Th/PCBM ternary blends was fixed to $x: 1-x: 1.5$. As shown in the figure, the PTB7Th/PCBM binary blend film exhibited an absorption valley in the visible region from 400 to $600 \mathrm{~nm}$. To enhance such a weak absorption, a wide-bandgap crystalline polymer PDCBT was added into the PTB7-Th/PCBM binary blend with the absorption of PTB7-Th kept constant. As a result, the absorption in the visible region at $400-600 \mathrm{~nm}$ increased upon the addition of PDCBT while the absorption PTB7-Th at around $710 \mathrm{~nm}$ remained the same. As shown in Figure 2b, the film thickness of these blends increased from 100 to $400 \mathrm{~nm}$ with an increase in the amount of PDCBT from 0 to $30 \mathrm{wt} \%$.

Figure 3 a shows the $J-V$ characteristics of PDCBT/PTB7Th/PCBM ternary blend solar cells with different weight ratios. All the ternary devices exhibited $J_{\mathrm{SC}}$ slightly higher than that for the binary control device. As shown in Figure 3b, the EQE signals at around $450 \mathrm{~nm}$ were as small as $40 \%$ for the PTB7$\mathrm{Th} / \mathrm{PCBM}$ binary device because of the absorption valley while they were improved to $70-80 \%$ for the ternary devices incorporating PDCBT. For the ternary blend solar cells, as summarized in Table $1, J_{\mathrm{SC}}$ was improved from $14.5 \mathrm{~mA} \mathrm{~cm}^{-2}$ at $0 \mathrm{wt} \%$ PDCBT to $15.1 \mathrm{~mA} \mathrm{~cm}^{-2}$ at $10 \mathrm{wt} \%$ PDCBT and then 
a)

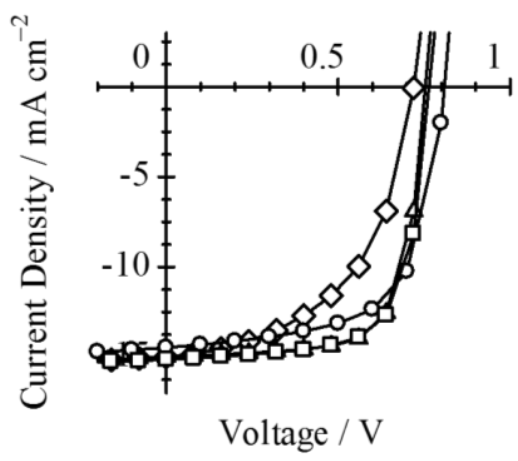

b)

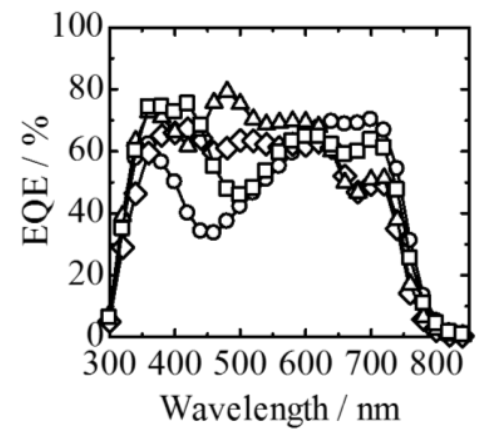

Figure 3. a) $J-V$ characteristics and b) EQE spectra of PDCBT/PTB7$\mathrm{Th} / \mathrm{PCBM}$ ternary blend polymer solar cells with the different PDCBT wt $\%$ : $0 \mathrm{wt} \%$ (open circles), $10 \mathrm{wt} \%$ (open squares), $20 \mathrm{wt} \%$ (open triangles), and $30 \mathrm{wt} \%$ (open diamonds).

Table 1. Photovoltaic parameters of PDCBT/PTB7-Th/PCBM ternary blend polymer solar cells with various weight fractions of PDCBT.

\begin{tabular}{cccccc}
\hline $\begin{array}{c}\text { PDCBT } \\
\mathrm{wt} \%\end{array}$ & $\begin{array}{c}J_{\mathrm{SC}} \\
/ \mathrm{mA} \mathrm{cm}^{-2}\end{array}$ & $\begin{array}{c}V_{\mathrm{OC}} \\
/ \mathrm{V}\end{array}$ & $\mathrm{FF}$ & $\begin{array}{c}\mathrm{PCE} \\
/ \%\end{array}$ & $\begin{array}{c}{ }^{\mathrm{a}} J_{\mathrm{SC}}{ }^{\text {calc }} \\
/ \mathrm{mA} \mathrm{cm}^{-2}\end{array}$ \\
\hline 0 & 14.5 & 0.81 & 0.64 & 7.52 & 14.0 \\
\hline 10 & 15.1 & 0.77 & 0.70 & 8.14 & 14.7 \\
\hline 20 & 15.0 & 0.76 & 0.71 & 8.10 & 15.3 \\
\hline 30 & 15.0 & 0.72 & 0.52 & 5.62 & 14.0 \\
\hline${ }^{\mathrm{a}} J_{\mathrm{SC}}{ }^{\text {calc }}$ values are calculated from the EQE and solar spectra.
\end{tabular}

decreased slightly to $15 \mathrm{~mA} \mathrm{~cm}{ }^{-2}$ above $20 \mathrm{wt} \%$ PDCBT whereas $V_{\mathrm{OC}}$ decreased from 0.81 to $0.72 \mathrm{~V}$ by adding PDCBT. Fill factor (FF) increased from 0.64 at $0 \mathrm{wt} \%$ PDCBT to 0.71 at $20 \mathrm{wt} \%$ PDCBT and then significantly decreased down to 0.52 at $30 \mathrm{wt} \%$ PDCBT. Such a large decrease in FF is probably ascribed to a poor charge collection efficiency to the electrodes, which results not only from the thicker active layer but also from insufficient interpenetrating networks of PTB7Th/PCBM disrupted by the presence of highly crystalline PDCBT. Consequently, the best performance was obtained for the ternary blend device with $10 \mathrm{wt} \%$ PDCBT: a $J_{\mathrm{SC}}$ of 15.1 $\mathrm{mA} \mathrm{cm}{ }^{-2}$, a $V_{\mathrm{OC}}$ of $0.77 \mathrm{~V}$, an FF of 0.70 , and an overall PCE of $8.14 \%$, which is higher than that $(7.52 \%)$ of the binary control device. Hereafter, the weight fraction of PDCBT was fixed to $10 \mathrm{wt} \%$.

We next examine the dependence of photovoltaic performance on the thickness of the photoactive layer. Figure 4 shows the photovoltaic parameters for PDCBT/PTB7Th/PCBM ternary and PTB7-Th/PCBM binary blend solar

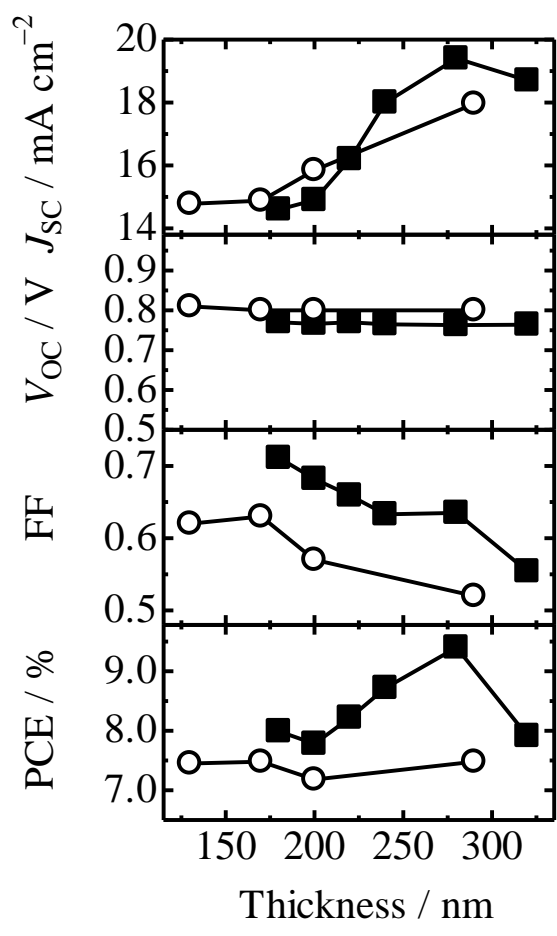

Figure 4. Photovoltaic parameters of PDCBT/PTB7-Th/PCBM ternary blend solar cells with the different PDCBT wt $\%$ as a function of the thickness of photoactive layer: $0 \mathrm{wt} \%$ (open circles) and $10 \mathrm{wt} \%$ (close squares).

cells plotted against the thickness of the photoactive layer. As shown in the figure, $J_{\mathrm{SC}}$ increased up to $18 \mathrm{~mA} \mathrm{~cm}$ for the binary blend and $19.4 \mathrm{~mA} \mathrm{~cm}^{-2}$ for the ternary blend cells with a thickness of $\approx 300 \mathrm{~nm}$. This is consistent with the increased EQE spectra as shown in Figure S1 (see Supporting Information (SI)). On the other hand, $V_{\mathrm{OC}}$ was nearly constant at around $0.80 \mathrm{~V}$ for the binary and $0.77 \mathrm{~V}$ for the ternary blend cells independently of the thickness of the photoactive layer. In contrast to $J_{\mathrm{SC}}, \mathrm{FF}$ decreased with increasing thickness of the photoactive layer: it decreased from 0.64 to 0.52 for the binary and from 0.71 to 0.55 for the ternary blend cells. Interestingly, FF was always higher for the ternary devices than for the binary devices. Consequently, the improved PCE was observed for the ternary devices with an increase in the thickness primarily because of the increase in $J_{\mathrm{SC}}$ whereas no improvement in PCE was observed for the binary devices because of the tradeoff relationship between $J_{\mathrm{SC}}$ and FF. As a result, the best device performance was obtained at a thickness of $\approx 300 \mathrm{~nm}$ for both devices, yielding a PCE of $7.48 \%$ for the binary and $9.40 \%$ for the ternary blend devices.

We finally address the origin of the improvement in FF for ternary blend devices. As mentioned above, although the FF decreased for both devices with increasing thickness of the photoactive layer, FF was as high as 0.60 even for a thickness of $\approx 300 \mathrm{~nm}$. This finding indicates that non-geminate recombination is effectively suppressed in the ternary blend devices. As reported previously, it has shown that polymer solar cells based on crystalline donor polymer and fullerene derivatives acceptor exhibit high FF because charge carriers 
can be efficiently collected even with a thick photoactive layer owing to suppressed non-geminate recombination compared to diffusion-limited Langevin recombination. ${ }^{15-18}$ In other words, the reduced non-geminate recombination is one of the key factors in the polymer solar cells with high FF. There are two possible mechanisms in our ternary blend system taking into account such idea. One passible mechanism is the hole transfer from PTB7-Th domains to crystalline PDCBT domains, which would lead to a spatial charge separation at the interface of PTB7-Th/PCBM because of cascaded energy structures, as reported previously. ${ }^{18,19}$ The other possible mechanism is ascribed to the improvement in the hole mobility of ternary blends due to reduced trap sites compared to that of the binary blends as reported previously. ${ }^{20,21}$ In such case, there would be a balanced charge transport between the hole and electron, giving rise to suppress the non-geminate recombination, and consequently the increase in FF. Further studies in terms of photophysical properties are required for an in-depth understanding the charge recombination dynamics in this ternary blend system.

In summary, the light harvesting efficiency in the ternary blend polymer solar cells, consisting of a wide-bandgap crystalline polymer PDCBT, a low-bandgap polymer PTB7-Th, and PCBM, can be markedly improved not only by broadening the absorption bandwidth due to the complementary absorption of ternary blends, but also by increasing the absorption efficiency due to the thick photoactive layer. With an increase in the amount of PDCBT as well as the thickness of photoactive layer, the maximum photocurrent of $19.4 \mathrm{~mA} \mathrm{~cm} \mathrm{mas}^{-2}$ wa obtained for the ternary blend device with $10 \mathrm{wt} \%$ PDCBT at a thickness of $280 \mathrm{~nm}$, being 1.34 times higher than that for the binary blend control device with a thickness of $130 \mathrm{~nm}$. On the other hand, $V_{\mathrm{OC}}$ was slightly higher in PTB7-Th/PCBM binary cells than in PDCBT/PTB7-Th/PCBM ternary blend solar cells because of the difference in HOMO level between PDCBT and PTB7-Th. Interestingly, the ternary blend device exhibited FF as high as 0.60 even for thick photoactive layer, which may be ascribed to the suppressed non-geminate recombination. As a result, the best PCE of $9.40 \%$ was obtained for PDCBT/PTB7Th/PCBM ternary blend solar cells, being 1.25 times higher than that for binary blend control device.

This study partly supported by the Japan Science and Technology Agency (JST) ALCA program (Solar Cell and Solar Energy Systems).

Supporting Information is available on http://dx.doi.org/10.1246/cl.******.

\section{References and Notes}

1 L. Lu, T. Zheng, Q. Wu, A. M. Schneider, D. Zhao, L. Yu, Chem. Rev. 2015, 115, 12666.
2 M. Wright, R. Lin, M. J. Y. Tayebjee, G. Conibeer, Sol. RRL 2017, 1,1700035 .

3 J. Zhao, Y. Li, G. Yang, K. Jiang, H. Lin, H. Ade, W. Ma, H. Yan, Nat. Energy 2016, 1, 15027.

4 J. Hou, O. Inganäs, R. H. Friend, F. Gao, Nat. Mater. 2018, 17, 119.

5 V. Vohra, K. Kawashima, T. Kakara, T. Koganezawa, I. Osaka, K. Takimiya, H. Murata, Nat. Photonics 2015, 9, 403.

6 W. Zhao, S. Li, H. Yao, S. Zhang, Y. Zhang, B. Yang, J. Hou, J. Am. Chem. Soc. 2017, 139, 7148.

7 K. Kawashima, Y. Tamai, H. Ohkita, I. Osaka, K. Takimiya, Nat. Commun. 2015, 6, 10085.

8 D. Baran, T. Kirchartz, S. Wheeler, S. Dimitrov, M. Abdelsamie, J. Gorman, R. S. Ashraf, S. Holliday, A. Wadsworth, N. Gasparini, P. Kaienburg, H. Yan, A. Amassian, C. J. Brabec, J. R. Durrant, I. McCulloch, Energy Environ. Sci. 2016, 9, 3783.

9 S. Honda, T. Nogami, H. Ohkita, H. Benten, S. Ito, ACS Appl. Mater. Interfaces 2009, 1, 804.

10 S. Honda, H. Ohkita, H. Benten, S. Ito, Adv. Energy Mater. 2011, 1,588 .

11 H. Xu, H. Ohkita, Y. Tamai, H. Benten, S. Ito, Adv. Mater. 2015, 27,5868 .

12 W. Zhao, S. Li, S. Zhang, X. Liu, J. Hou, Adv. Mater. 2017, 29, 1604059.

13 G. Zhang, K. Zhang, Q. Yin, X.-F. Jiang, Z. Wang, J. Xin, W. Ma, H. Yan, F. Huang, Y. Cao, J. Am. Chem. Soc. 2017, 139, 2387.

14 C. Wang, W. Zhang, X. Meng, J. Bergqvist, X. Liu, Z. Genene, X. Xu, A. Yartsev, O. Inganäs, W. Ma, E. Wang, M. Fahlman, Adv. Energy Mater. 2017, 7, 1700390.

15 G. F. A. Dibb, F. C. Jamieson, A. Maurano, J. Nelson, J. R. Durrant J. Phys. Chem. Lett. 2013, 4, 803.

16 X. Guo, N. Zhou, S. J. Lou, J. Smith, D. B. Tice, J. W. Hennek, R. P. Ortiz, J. T. L. Navarrete, S. Li, J. Strzalka, L. X. Chen, R. P. H. Chang, A. Facchetti, T. J. Marks, Nat. Photonics 2013, 7, 825.

17 K. Kawashima, T. Fukuhara, Y. Suda, Y. Suzuki, T. Koganezawa, H. Yoshida, H. Ohkita, I. Osaka, K. Takimiya, J. Am. Chem. Soc. 2016, 138, 10265.

18 T. Fukuhara, M. Osaka, Y. Tamai, H. Hideo, H. Benten, S. Ito, $J$. Photopolym. Sci. Technol. 2016, 29, 575.

19 K. Nakano, K. Suzuki, Y. Chen, K. Tajima, Sci. Rep. 2016, 6, 29529.

20 B. Tan, H. Pan, H. Li, M. L. Minus, B. M. Budhlall, M. J. Sobkowicz, J. Phys. Chem. C 2018, 122, 2918.

21 V. Bharti, A. Sharma, V. Gupta, G. D. Sharma, S. Chand, Appl. Phys. Lett. 2016, 108, 073505. 